\title{
Brain Changes in Older Adults at Very Low Risk for Alzheimer's Disease
}

\author{
Anders M. Fjell, ${ }^{1}$ Linda McEvoy, ${ }^{2}$ Dominic Holland, ${ }^{2,3}$ Anders M. Dale, ${ }^{2,3,4}$ and Kristine B. Walhovd ${ }^{1}$ for the Alzheimer's \\ Disease Neuroimaging Initiative* \\ ${ }^{1}$ Research Group for Lifespan Changes in Brain and Cognition, Department of Psychology, University of Oslo, 0317 Oslo, Norway, ${ }^{2}$ Multimodal Imaging \\ Laboratory and ${ }^{3}$ Department of Neurosciences, University of California, San Diego, California 92093, and ${ }^{4}$ Department of Radiology, University of \\ California, San Diego, California 92103
}

\begin{abstract}
Alzheimer's disease (AD) has a slow onset, so it is challenging to distinguish brain changes in healthy elderly persons from incipient AD. One-year brain changes with a distinct frontotemporal pattern have been shown in older adults. However, it is not clear to what extent these changes may have been affected by undetected, early AD. To address this, we estimated 1-year atrophy by magnetic resonance imaging (MRI) in 132 healthy elderly persons who had remained free of diagnosed mild cognitive impairment or AD for at least 3 years. We found significant volumetric reductions throughout the brain. The sample was further divided into low-risk groups based on clinical, biomarker, genetic, or cognitive criteria. Although sample sizes varied, significant reductions were observed in all groups, with rates and topographical distribution of atrophy comparable to that of the full sample. Volume reductions were especially pronounced in the default mode network, closely matching the previously described frontotemporal pattern of changes in healthy aging. Atrophy in the hippocampus predicted change in memory, with no additional default mode network contributions. In conclusion, reductions in regional brain volumes can be detected over the course of 1 year even in older adults who are unlikely to be in a presymptomatic stage of AD.
\end{abstract}

\section{Introduction}

Current models of Alzheimer's disease (AD) posit that brain atrophy progresses years before clinical symptoms appear (Jack et

Received Nov. 12, 2012; revised Feb. 26, 2013; accepted March 26, 2013

Author contributions: A.M.F. and K.B.W. designed research; A.M.F., L.M., D.H., A.M.D., and K.B.W. performed research; A.M.F. analyzed data; A.M.F. and K.B.W. wrote the paper.

This work was supported by the Norwegian Research Council (Grant \#177404 and Grant \#186092 to K.B.W.; Grant \#175066 and \#189507 to A.M.F.), the University of 0slo (to K.B.W. and A.M.F.), the European Research Council Starting Grant Scheme (to K.B.W. and A.M.F.), the National Institute on Aging-National Institutes of Health (Grant\#R01AG031224 to A.M.D. and Grant\#K01AG029218 to L.K.M.), and the National Institutes of Health (Grant\#P30 AG010129 and Grant\#K01 AG030514). Data collection and sharing for this project were funded by the Alzheimer's Disease Neuroimaging InitiativeNational Institutes of Health (Grant\#U01 AG024904). The Alzheimer's Disease Neuroimaging Initiative is also funded by the National Institute of Biomedical Imaging and Bioengineering and by generous contributions from the following: Abbott; Alzheimer's Association; Alzheimer's Drug Discovery Foundation; Amorfix Life Sciences, Ltd.; AstraZeneca; Bayer HealthCare; BioClinica, Inc.; Biogen Idec, Inc.; Bristol-Myers Squibb Company; Eisai, Inc.; Elan Pharmaceuticals, Inc.; Eli Lilly and Company; F. Hoffmann-La Roche, Ltd., and its affiliated company, Genentech, Inc;; GE Healthcare; Innogenetics, N.V.;IXICO, Ltd.; Janssen Alzheimer Immunotherapy Research and Development, LLC.; Johnson and Johnson Pharmaceutical Research and Development, LLC.; Medpace, Inc.; Merck and Co., Inc;; Meso Scale Diagnostics, LLC.; Novartis Pharmaceuticals Corporation; Pfizer, Inc.; Servier; Synarc, Inc.; and Takeda Pharmaceutical Company. The Canadian Institutes of Health Research is providing funds to support Alzheimer's Disease Neuroimaging Initiative clinical sites in Canada. Private sector contributions are facilitated by the Foundation for the National Institutes of Health (www.fnih.org). The grantee organization is the Northern California Institute for Research and Education and the study is coordinated by the Alzheimer's Disease Cooperative Study at the University of California, San Diego. Alzheimer's Disease Neuroimaging Initiative data are disseminated by the Laboratory for Neuro Imaging at the University of California, Los Angeles.

A.M.D. is a founder and holds equity in CorTechs Labs, Inc., and also serves on the scientific advisory board. The terms of this arrangement have been reviewed and approved by the University of California, San Diego, in accordance with its conflict-of-interest policies. L.M.'s spouse is president of CorTechs Labs, Inc. The remaining authors declare no competing financial interests.

*Some of the data used in the preparation of this article were obtained from the ADNI database (adni.loni.u(la.edu). As such, the investigators within the ADNI contributed to the design and implementation of ADNI and/or provided data, but did not participate in analysis or writing of this report. A complete listing of ADNI investigators can be found at: adni.Ioni.ucla.edu/wp-content/uploads/how_to_apply/ADNI_Acknowledgement_List.pdf.

Correspondence should be addressed to Anders M. Fjell, Department of Psychology, University of Oslo, PO Box 1094 Blindern, 0317 0slo, Norway. E-mail: andersmf@psykologi.uio.no.

DOI:10.1523/JNEUROSCI.5506-12.2013

Copyright $\odot 2013$ the authors $\quad 0270-6474 / 13 / 338237-06 \$ 15.00 / 0$ al., 2011; Sperling et al., 2011), and possibly that nerve cell degeneration is downstream from earlier causative events, especially abnormal processing of amyloid- $\beta$ peptides (Goedert and Spillantini, 2006; Jack et al., 2010). This makes it very difficult to disentangle brain changes in normal aging from the earliest signs of AD Using data from the Alzheimer's Disease Neuroimaging Initiative (ADNI, www.adni-info.org), we have shown previously that significant reductions in regional cortical volumes can be reliably detected over periods as short as 1 year (Fjell et al., 2009) or less (Murphy et al., 2010) in healthy elderly persons, and that thinning of the entorhinal cortex can be found in participants at low risk for $\mathrm{AD}$ (Fjell et al., 2012). However, long-term follow-up data have been lacking, making it difficult to be certain that the changes observed were not influenced by presymptomatic $\mathrm{AD}$ pathology. This is an important consideration given the prominent temporal changes that were observed in previous studies (Fjell et al., 2009), which overlapped in topography with the atrophy seen in mild cognitive impairment (MCI) and $\mathrm{AD}$ (Jack et al., 1997; McDonald et al., 2009). With the continuation of ADNI, additional longer term follow-up data are now available for participants included in previous studies (Fjell et al., 2009; 2012). In an attempt to disentangle the characteristics of normal aging from those of presymptomatic $\mathrm{AD}$, we took advantage of these new data to examine brain changes in those elderly persons at very low risk of developing $\mathrm{AD}$. We used a combination of 3- to 4-year follow-up examinations with clinical instruments and neuropsychological memory tests, established CSF biomarkers of amyloid pathology (Blennow and Hampel, 2003; Strozyk et al., 2003; Blennow et al., 2006), and the genetic risk factor apolipoprotein $\varepsilon 4$ to assign participants to different low-risk groups. We were able to study longitudinal brain changes in these low-risk 
elderly persons and to be more confident that any changes observed were not due to presymptomatic AD.

\section{Materials and Methods}

Sample. The principal investigator for ADNI is Michael W. Weiner (Veterans Administration Medical Center and University of CaliforniaSan Francisco). ADNI eligibility criteria are described at www.adni-info.org. Briefly, participants were 55-91 years of age at baseline, had an informant able to provide an independent evaluation of functioning, and spoke either English or Spanish. General inclusion/ exclusion criteria were as follows for normal subjects: Mini-Mental State Examination (MMSE; Folstein et al., 1975) scores between 24 and 30 (inclusive), Clinical Dementia Rating (CDR; Morris, 1993) of 0, nondepressed, non-MCI, and nondemented. A total of 162 healthy elderly (60-90 years) persons fulfilling these criteria and with 1-year longitudinal MRI passing internal quality control were available (Holland et al., 2009). Of these, 8 converted to $\mathrm{MCI} / \mathrm{AD}$ within 3 years and 22 did not complete the 3-year examination, yielding 132 eligible datasets (age 60-90 years, mean $75.4 \pm 5.1$ years, 63 females $/ 69$ males) with at least 3 years of follow-up data. For 80 of these participants, 4-year follow-up data were available, with 1 additional conversion to $\mathrm{MCI} / \mathrm{AD}$, yielding 79 eligible 4-year datasets (age 60-90 years, mean $75.8 \pm 5.3$ years, 38 females/41 males).

Clinical, biomarker, and cognitive criteria were used to assign participants to low-risk groups. The clinically defined group $(n=79)$ showed no change in the CDR sum of boxes or MMSE scores for 3 years. The biomarker-defined group $(n=37)$ consisted of participants with normal levels of baseline CSF amyloid- $\beta_{1-42}$ based on an established criterion from the ADNI (i.e., $\geq 192 \mathrm{pg} / \mathrm{ml}$; Shaw et al., 2009) who were negative for apolipoprotein $\varepsilon 4$ (Corder et al., 1993). CSF was obtained from approximately half the total ADNI sample. The memory low-risk group $(n=42)$ obtained at least $90 \%$ of their baseline score on the learning and 30 min recall measures from the Rey Auditory Verbal Learning Test (RAVLT; Rey, 1964) at the 3-year follow-up examination.

For comparison purposes, we also included a groups of high-risk, nondemented elderly persons, consisting of participants with a stable MCI diagnosis for 3 years $(n=213)$, as well as a group of $\mathrm{AD}(n=122)$ patients. Years of education were comparable across low-risk groups (15.7-16.4 years), MCI (15.8 years), and AD (15.0 years) patients.

MRI acquisition and analysis. All scans were from $1.5 \mathrm{~T}$ scanners collected across a variety of scanners with protocols individualized for each scanner as defined at adni.loni.ucla.edu/methods/documents mri-protocols/ Rates of volumetric change were calculated using Quarc (Holland et al., 2009, 2011, 2012). Methodological bias in image registration can artifactually elevate effect sizes, constituting a concern in neuroimaging studies (Thompson et al., 2011). Several robust approaches to reducing or eliminating bias have been developed (Leung et al., 2012; Reuter et al., 2012). Quarc uses an explicit inverse-consistent approach (Holland et al., 2011) that essentially eliminates potential bias by combining forward and reverse image registrations and has been favorably compared with other approaches (Holland et al., 2012). Briefly, for each participant, dual 3-D follow-up structural scans were rigid-body aligned, averaged, and affine aligned to the participant's baseline. A deformation field was calculated from a nonlinear registration (Holland et al., 2011). The images are heavily blurred (smoothed), making them almost identical, and a merit or potential function was calculated. This merit function expresses the intensity difference between the images at each voxel and depends on the displacement field for the voxel centers of the image being transformed. The merit function by design will have a minimum when the displacement field induces a good match between the images. Having found a displacement field for the heavily blurred pair of images, the blurring is reduced and the procedure is repeated, thus iteratively building up a better displacement field. The final displacement field is added to the image being transformed and the resultant image nonlinearly registered to the same target and finally traced back through the displacement field thus calculated to find the net displacement field. This enables very precise registration, even at small spatial scales with low boundary contrast. Nonphysical deformations are precluded because, at each level of blurring, the image undergoing deformation is restricted to conform to the target. This deformation field was used to align scans at the subvoxel level. To obtain volume change estimates in a large number of regions, we used a well validated image segmentation and parcellation approach (Fischl et al., 2002, 2004).

Statistical analyses. The percentage change in cortical volume over 1 year was calculated, color coded, and projected onto a semi-inflated template brain. General linear models were used to test vertex-wise change across the cortical surface, corrected for multiple comparisons across vertices by a false discovery rate $<0.05$. Change in volumetric regions of interest (ROIs) were tested by one-sample $t$ tests and the $p$-values adjusted for number of regions by Bonferroni corrections by a factor of 17 (similar to an uncorrected $p=0.003$ ). The surface plots were then $z$-transformed within each group separately to allow inspection of the areas with higher or lower than average rates of atrophy for each group of participants. The topographical distribution of change in the $z$-maps was also compared with change in groups of 3-year stable MCI and $\mathrm{AD}$ patients.

The default mode network (DMN) was given special attention in the analyses (Raichle et al., 2001; Buckner et al., 2008; Drzezga et al., 2011). DMN overlaps substantially with a network of core brain areas involved in episodic memory and imagination (Buckner and Carroll, 2007; Schacter et al., 2007), which are affected both in normal aging (AndrewsHanna et al., 2007; Addis et al., 2011) and in AD (Walhovd et al., 2010; 
Table 1. Annual atrophy in low-risk healthy controls

\begin{tabular}{|c|c|c|c|c|c|c|c|c|c|c|}
\hline & \multicolumn{2}{|c|}{$\begin{array}{l}\text { Healthy } 3 \text { years } \\
(n=132)\end{array}$} & \multicolumn{2}{|c|}{$\begin{array}{l}\text { Healthy } 4 \text { years } \\
(n=79)\end{array}$} & \multicolumn{2}{|c|}{$\begin{array}{l}\text { Clinically stable } 3 \text { years } \\
(n=79)\end{array}$} & \multicolumn{2}{|c|}{$\begin{array}{l}\text { A } \beta / \text { APOE negative } \\
(n=37)\end{array}$} & \multicolumn{2}{|c|}{$\begin{array}{l}\text { Memory stable } 3 \text { years } \\
(n=42)\end{array}$} \\
\hline & $\%$ & SD & $\%$ & SD & $\%$ & SD & $\%$ & SD & $\%$ & SD \\
\hline \multicolumn{11}{|l|}{ Volumetric ROIs } \\
\hline Whole-brain & -0.44 & 0.74 & -0.45 & 0.70 & -0.38 & 0.73 & -0.35 & 0.71 & -0.43 & 0.63 \\
\hline Accumbens & -0.57 & 1.23 & -0.64 & 1.32 & -0.43 & 1.10 & -0.28 & 1.34 & -0.50 & 1.03 \\
\hline Amygdala & -0.99 & 1.50 & -1.00 & 1.52 & -0.82 & 1.59 & -0.72 & 1.21 & -0.93 & 1.45 \\
\hline Brainstem & -0.36 & 0.77 & -0.36 & 0.77 & -0.30 & 0.79 & -0.37 & 0.64 & -0.29 & 0.58 \\
\hline Caudate & -0.21 & 1.25 & -0.26 & 1.39 & -0.07 & 1.28 & 0.08 & 0.98 & -0.19 & 0.82 \\
\hline Cerebellum GM & -0.43 & 0.83 & -0.42 & 0.83 & -0.39 & 0.86 & -0.45 & 0.85 & -0.33 & 0.83 \\
\hline Cerebellum WM & -0.53 & 0.72 & -0.54 & 0.75 & -0.47 & 0.75 & -0.45 & 0.65 & -0.53 & 0.58 \\
\hline Cerebral GM & -0.49 & 1.04 & -0.54 & 1.02 & -0.36 & 1.01 & -0.30 & 0.81 & -0.52 & 0.94 \\
\hline Cerebral WM & -0.49 & 0.65 & -0.49 & 0.56 & -0.45 & 0.66 & -0.42 & 0.66 & -0.48 & 0.56 \\
\hline Hippocampus & -1.06 & 1.23 & -0.99 & 1.26 & -0.93 & 1.01 & -0.97 & 1.04 & -1.05 & 1.22 \\
\hline Pallidum & -0.41 & 0.72 & -0.43 & 0.67 & -0.38 & 0.73 & -0.21 & 0.68 & -0.45 & 0.54 \\
\hline Putamen & -0.37 & 0.74 & -0.40 & 0.80 & -0.30 & 0.69 & -0.17 & 0.68 & -0.34 & 0.56 \\
\hline Thalamus & -0.62 & 0.84 & -0.66 & 0.88 & -0.52 & 0.81 & -0.38 & 0.70 & -0.72 & 0.71 \\
\hline \multicolumn{11}{|l|}{ Ventricular ROIs } \\
\hline Ventricles, total & 4.09 & 4.83 & 4.57 & 4.49 & 3.57 & 4.34 & 2.78 & 3.67 & 4.34 & 4.27 \\
\hline Lateral ventricle & 4.13 & 4.88 & 4.61 & 4.55 & 3.62 & 4.43 & 2.86 & 3.66 & 4.44 & 4.44 \\
\hline Inferior lateral ventricle & 4.21 & 6.34 & 4.63 & 5.90 & 3.27 & 5.22 & 2.24 & 4.67 & 3.73 & 4.92 \\
\hline Third ventricle & 2.90 & 4.66 & 3.13 & 3.90 & 2.37 & 4.34 & 2.07 & 3.26 & 3.08 & 4.06 \\
\hline Fourth ventricle & 0.49 & 3.95 & 0.99 & 3.99 & 0.06 & 3.62 & -0.14 & 4.25 & 0.85 & 3.64 \\
\hline
\end{tabular}

Annual percentage change in volume calculated from baseline to 1 year follow-up. Participants are assigned to groups based on various criteria: diagnostic stability $>3$ years from baseline, 4 years from baseline, no reduction over 3 years in the CDR sum of boxes (CDR-sb) or MMSE scores, no apolipoprotein $\epsilon 4$ (APOE) alleles, and high CSF levels of amyloid- $\beta 1-42$ (A $\beta_{1-42}$, indicating low brain levels of $A \beta$ ) or stability of memory performance over 3 years (at least $90 \%$ of initial score in the AVLT learning and 30 min delayed recall task). Note that the same participants are included in numerous groups (e.g., all are included in the 3 year diagnostic stable group). The volume change was averaged across hemispheres. Bold characters indicate $p<0.05$, corrected (Bonferroni corrected for 17 regions, not including whole brain, uncorrected threshold of $p=0.003$ ).

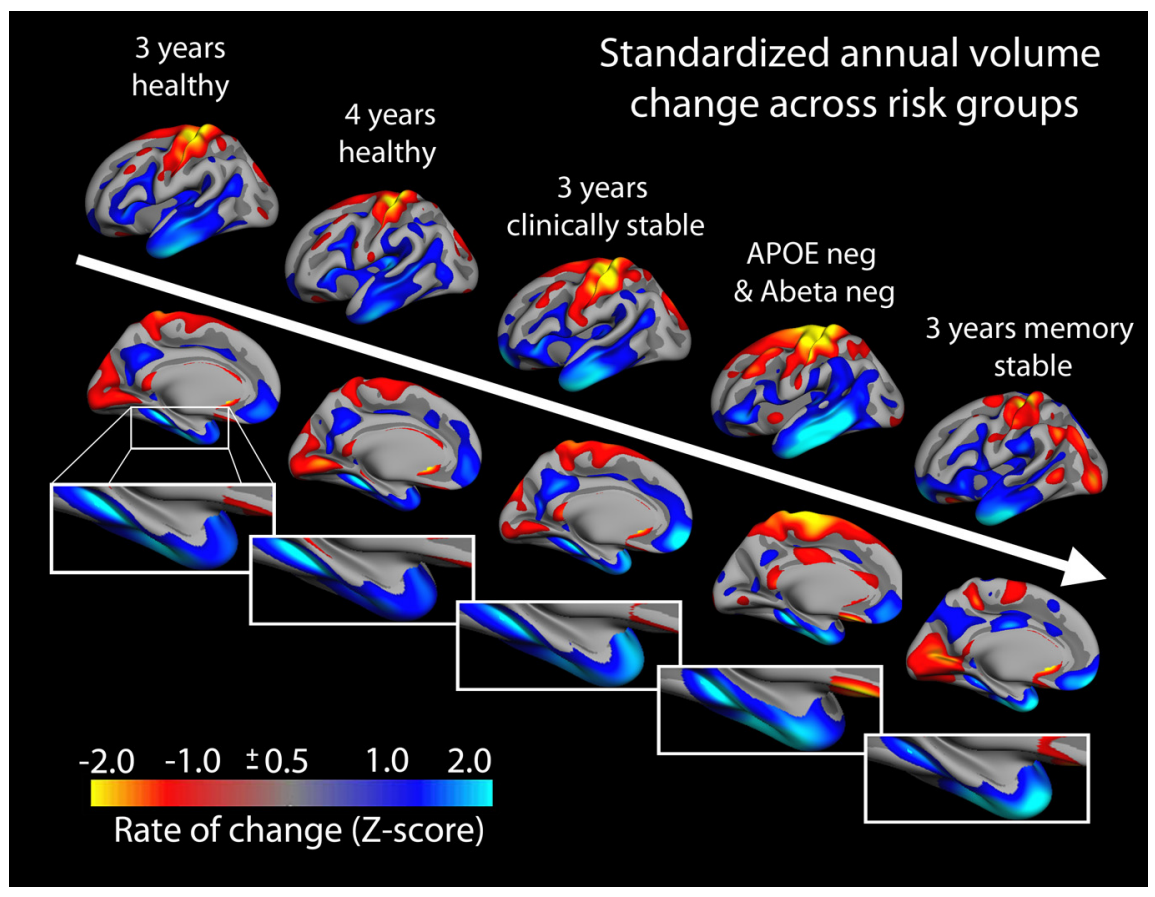

Figure 2. Pattern of atrophy in low-risk healthy elderly persons. Annual atrophy was standardized for each group, yielding maps showing areas of more (blue-cyan) versus less (red-yellow) relative atrophy expressed in units of SDs (z-scores). As can be seen, the pattern of atrophy is distinctly frontotemporal, with some evidence of medial parietal atrophy (precuneus/retrosplenial cortex) as well. Abeta indicates amyloid- $\beta$; APOE, apolipoprotein $\varepsilon 4$.

Jones et al., 2011). Based on recent normative studies (Laird et al., 2009; Andrews-Hanna et al., 2010), we selected seven regions within the default mode or episodic memory/simulation network: the rostral middle frontal, inferior parietal cortex and middle temporal cortex on the lateral side and the medial orbitofrontal cortex, precuneus, entorhinal cortex and the hippocampus on the medial side (although the role played by the hippocampus is debated; Nyberg et al., 2010; Squire et al., 2010). Pairedsample $t$ tests were used to determine whether the rate of change within the lateral and medial part of DMN differed from the rate of whole-brain change.

Finally, because DMN is implicated in episodic memory, the relationship between DMN change and the 1-year change in learning and 30-min recall performance from the RAVLT was tested by the use of hierarchical multiple regression analyses. Age, sex, education, and whole-brain atrophy rate were entered as covariates, hippocampal change as the first predictor of interest, with change in learning or 30 -min recall as the dependent variables, in separate models. Whole-brain atrophy rate was included as a covariate to assess the specificity of the relationship of regional change with memory change. In the next steps, the other medial DMN and the lateral DMN regions were sequentially entered as predictor variables to determine whether atrophy rates in these areas explained additional variance in memory scores and if they attenuated the relationship between hippocampal atrophy and memory change.

\section{Results}

Change rates across the groups of nondemented older adults are shown in Figure 1 and Table 1. For the total group of 3-year healthy participants, significant cortical reduction ( $p<0.05$, corrected for multiple comparisons) was seen across most of the cortex, with a mean rate of annual cortical change of $0.40 \%$ across hemispheres. The largest reductions were observed in temporal areas, followed by prefrontal cortex. Of the volumetric ROIs, hippocampus (1.01\%) and amygdala $(0.99 \%)$ declined the most and all regions except caudate declined significantly over 1 year. All parts of the ventricular system except the fourth ventricle expanded significantly. Significant at- 
rophy was observed in all medial and lateral DMN regions, and these regions showed significantly higher annual atrophy rates than the whole-brain rate of $0.44 \%$ (medial: $0.70 \%, t_{(131)}=4.75$, $p<10^{-5}$ /lateral: $\left.0.53 \%, t_{(131)}=2.10, p<0.05\right)$.

Rates and topographical distribution of atrophy in all low-risk subgroups were generally comparable to the 3-year healthy group. Although sample size varied between groups, all low-risk subgroups showed significant reductions across the brain and ventricular expansion. Significant decline was seen across most temporal and frontal cortices. The only part of the cortex that was consistently not reduced was the area around the central sulcus. For the volumetric regions, hippocampus and amygdala showed the largest annual declines across low-risk groups.

The atrophy maps in Figure 1 were $z$-transformed to illustrate areas of more versus less relative change for each group (Fig. 2). Again, the pattern was remarkably stable across the groups. Higher than average atrophy was seen in medial and lateral parts of the temporal lobe, medial and lateral orbitofrontal cortex, and precuneus/retrosplenial cortex. This pattern overlapped well with DMN. Less than average change was seen around the central sulcus, the posterior parts of the superior frontal cortex, and primary visual cortices.

To allow direct comparison with high-risk nondemented elderly participants (MCI) and AD patients while suppressing differences due to the overall differences in rate of atrophy, similar maps were generated for 213 stable MCI and 122 stable AD patients (Fig. 3). The pattern of atrophy in medial and lateral temporal areas was very similar in MCI and AD patients to that seen in the healthy elderly persons. The main topographical difference in atrophy pattern between the low-risk elderly and the MCI/AD patients was that healthy adults showed higher than average atrophy in the orbitofrontal cortex and rostral middle/inferior frontal cortex; atrophy in these regions in $\mathrm{AD}$ and MCI patients was not elevated relative to average atrophy rates across the cortex.

The hierarchic multiple regression analyses showed that after controlling for age, sex, education, and whole-brain atrophy, hippocampal atrophy significantly predicted memory change (learning: standardized $\beta=0.25, p<0.01$; recall $\beta=0.28, p<$ $0.005)$. Including the other medial DMN regions or the lateral DMN regions as additional predictors did not significantly increase the amount of explained variance in memory change and did not attenuate the relationship between hippocampus and memory.

\section{Discussion}

Even in groups of healthy elderly persons at very low risk of $\mathrm{AD}$, volumetric reductions and ventricular expansion were detectable over 1 year. This suggests that not all brain changes in aging reflect incipient $\mathrm{AD}$, but rather that volume reductions are a general feature of normal aging. The newly available follow-up data enabled us to test whether previously observed brain changes over short time windows in aging (Fjell et al., 2009; Murphy et al., 2010) occur in those with very low AD risk. Although most of the brain showed significant volume reductions, areas of greatest change aligned well with the DMN, which has been shown to be affected both in normal aging (Andrews-Hanna et al., 2007; Addis et al., 2011) and in AD (Walhovd et al., 2010; Jones et al., 2011). We have shown previously that whereas healthy elderly are characterized by elevated frontotemporal cortical changes relative to other cortical regions, $\mathrm{AD}$ patients show elevated atrophy in the temporal regions, with a lesser degree of relative atrophy in the prefrontal cortex (Fjell et al., 2009). The present results pro-

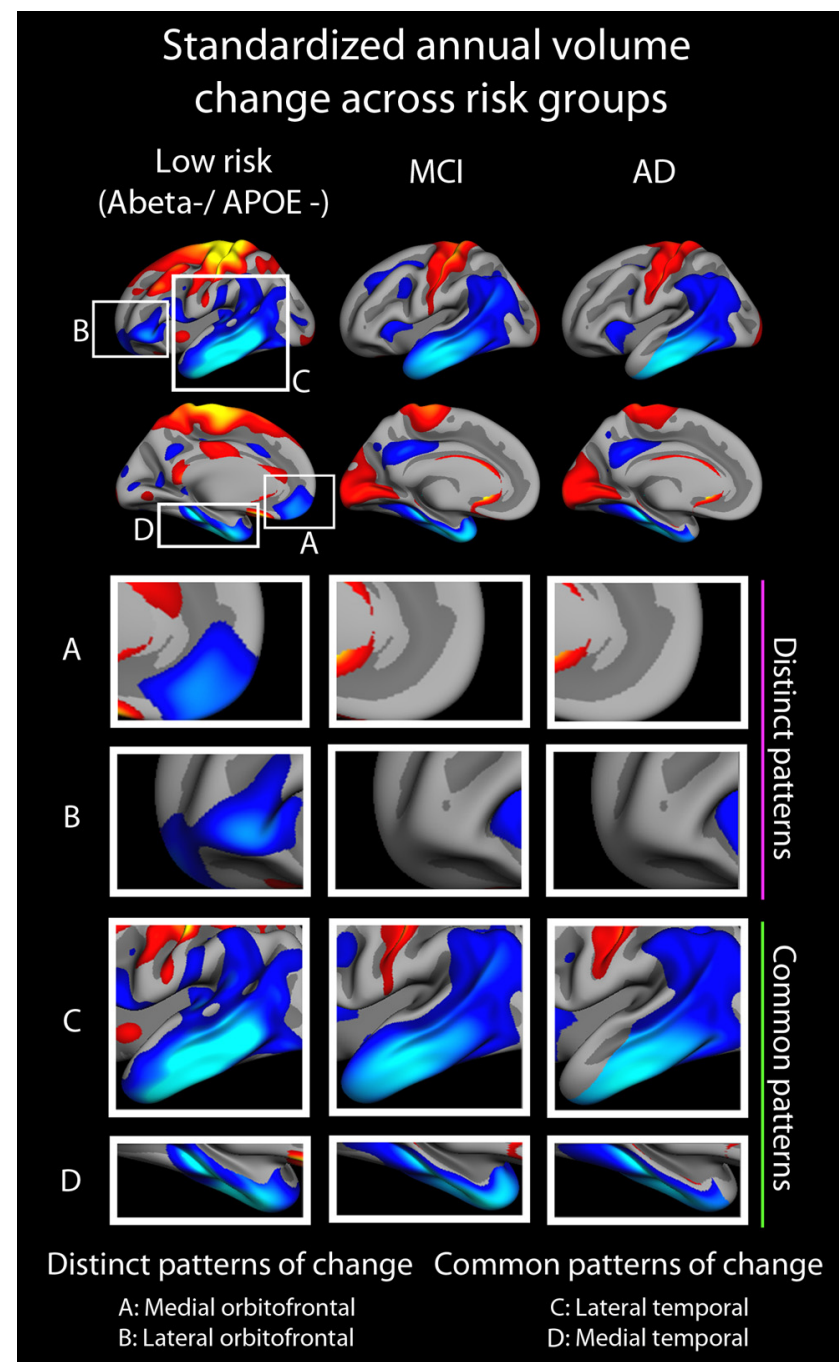

Figure 3. Comparison of low-risk aging and MCl/AD. Shown is a comparison of the standardized pattern of atrophy in the group of apolipoprotein $\varepsilon 4$ (APOE $\varepsilon 4)$-negative elderly with normal levels of CSF amyloid- $\beta$ (Abeta), $\mathrm{MCl}$, and AD. Atrophy maps are standardized within each group, yielding maps showing areas of more (blue-cyan) versus less (red-yellow) atrophy for each group. Therefore, atrophy is scaled within group and changes are relative to group means. Across groups, we see common patterns of standardized change in the lateral and medial temporal lobe (including the hippocampus, data not shown), and a distinct pattern characterizing only healthy elderly in the prefrontal cortex, especially the orbitofrontal part.

vide further support that the temporal pattern of changes characterize elderly who are indeed healthy.

Several studies have demonstrated significant reductions in brain volumes in healthy elderly in the ADNI sample (Fjell et al., 2009; Murphy et al., 2010) and in other populations (Raz et al., 2005; Driscoll et al., 2009). The general problem is that if ADrelated pathology is manifest in the brain years before cognitive symptoms are detected by clinical screening instruments (Jack et al., 2010), it is challenging to convincingly show that the brain changes are not driven by preclinical AD. For example, a person dying at age 79 will have a $30-40 \%$ probability of significant AD neuropathological changes in the brain, but only a $15 \%$ likelihood of having being diagnosed with dementia due to $\mathrm{AD}$ (Nelson et al., 2012). Therefore, it has been suggested that the often observed age-related atrophy may be due to insufficient screening for neurodegenerative disease (Burgmans et al., 2009). Driscoll et al. (2009) convincingly argued that the pattern of change observed in their large study of normal aging did not 
resemble that seen in $\mathrm{MCI}$, indicating non-AD-related brain changes in healthy elderly. The present results show that even in elderly at very low risk of $\mathrm{AD}, 1$-year brain changes are detectable across most areas of the brain. Although we cannot be sure that none of the low-risk participants in the present study will eventually develop $\mathrm{AD}$, the likelihood that a large proportion of the participants in these different subgroups are showing AD-related brain atrophy is small. Therefore, the brain changes observed here most likely reflect features of normal, non-AD-related aging.

Medial temporal lobe (MTL) atrophy appears to be common to normal aging and AD. Even though hippocampus and entorhinal cortex are the areas that best distinguish $\mathrm{AD}$ from controls in terms of rate of atrophy (Fjell et al., 2010), low-risk elderly also show accelerated changes in these areas. One speculation is that areas characterized by a high degree of life-long plasticity are also among those most vulnerable to detrimental effects of normal and pathological aging. Relationships between MTL changes and memory have been shown in previous longitudinal studies (Rodrigue and Raz, 2004; Murphy et al., 2010; Persson et al., 2012), and the current results demonstrate that such relationships exist even in low-risk elderly. The causal direction of the relationship cannot be inferred from these correlational results, because both targeted cognitive interventions (Engvig et al., 2010; Zatorre et al., 2012) and lifespan mental activity (Valenzuela et al., 2008) have been shown to affect brain atrophy.

According to a unitary factor framework, mild memory decline in aging exists along a continuum with memory impairment in $\mathrm{AD}$, and dementia is considered to be an acceleration of processes that affect cognition in normal aging (Buckner, 2004). This fits with the "brain maintenance" hypothesis, in which maintenance of structural integrity is important for high cognitive function in aging (Nyberg et al., 2012). In contrast, a multiple factor framework would hold that separate factors affect cognition in aging, with distinct causes, anatomical targets, and cognitive consequences. A popular view is that whereas MTL atrophy causes memory problems in AD (Jack et al., 2010), normal aging affects frontostriatal circuits, leading to reduced executive function and secondary memory problems (Buckner, 2004). When absolute rates of changes were ignored, it was the orbitofrontal cortex rather than the MTL that differed most between healthy elderly and high-risk nondemented elderly (MCI) and AD patients (Fjell et al., 2009). Nevertheless, orbitofrontal changes did not correlate with memory function changes in the present study. Therefore, although it is likely that a multiple factor framework is mainly correct, the present results indicate that at the macroscopic level, $\mathrm{AD}$ and healthy aging still share at least one common substrate for changes in memory performance.

The current results point to a frontotemporal vulnerability in low-risk elderly and in $\mathrm{AD}$, overlapping with major hubs of the DMN. It is possible that these changes reflect changes common to age; however, it is also necessary to consider the possibility of other shared pathological changes, such as changes related to cerebrovascular disease (CVD). CVD increases in prevalence with age, has profound impact on brain structure and cognitive function (Leritz et al., 2011; Jennings et al., 2012), including hippocampus (Raz et al., 2005) and episodic memory (GunningDixon and Raz, 2000), and is a risk factor for AD. In a recent review, Jagust (2013) argued that CVD affects both major neural systems associated with aging-the prefrontal or executive and the medial temporal lobe memory system. Nelson et al. (2011)proposed that CVD may be a major pathology reflected in diagnosed dementia. Therefore, the overlapping pattern of change seen across low-risk healthy elderly and patients diagnosed with MCI or AD may reflect influences by factors such as CVD on temporal and frontal atrophy rates, with additional atrophy in temporal lobe regions in MCI and $\mathrm{AD}$ caused by other pathological processes. Interestingly, in a recent study, Carmichael et al. (2012)quantified interregional covariance in cortical atrophy rates in amnestic MCI patients by the use of a completely datadriven approach and argued for a pattern of frontal aging superimposed on medial temporal atrophy and DMN changes in these patients.

In conclusion, the present results show that 1-year brain changes are detectable in healthy elderly at very low risk of $\mathrm{AD}$ and that the pattern of change overlaps closely with the DMN, with hippocampal changes related to changes in episodic memory function.

\section{References}

Addis DR, Roberts RP, Schacter DL (2011) Age-related neural changes in autobiographical remembering and imagining. Neuropsychologia 49: 3656-3669. CrossRef Medline

Andrews-Hanna JR, Snyder AZ, Vincent JL, Lustig C, Head D, Raichle ME, Buckner RL (2007) Disruption of large-scale brain systems in advanced aging. Neuron 56:924-935. CrossRef Medline

Andrews-Hanna JR, Reidler JS, Sepulcre J, Poulin R, Buckner RL (2010) Functional-anatomic fractionation of the brain's default network. Neuron 65:550-562. CrossRef Medline

Blennow K, Hampel H (2003) CSF markers for incipient Alzheimer's disease. Lancet Neurol 2:605-613. CrossRef Medline

Blennow K, de Leon MJ, Zetterberg H (2006) Alzheimer's disease. Lancet 368:387-403. CrossRef Medline

Buckner RL (2004) Memory and executive function in aging and AD: multiple factors that cause decline and reserve factors that compensate. Neuron 44:195-208. CrossRef Medline

Buckner RL, Carroll DC (2007) Self-projection and the brain. Trends Cogn Sci 11:49-57. CrossRef Medline

Buckner RL, Andrews-Hanna JR, Schacter DL (2008) The brain's default network: anatomy, function, and relevance to disease. Ann N Y Acad Sci 1124:1-38. CrossRef Medline

Burgmans S, van Boxtel MP, Vuurman EF, Smeets F, Gronenschild EH, Uylings HB, Jolles J (2009) The prevalence of cortical gray matter atrophy may be overestimated in the healthy aging brain. Neuropsychology 23:541-550. CrossRef Medline

Carmichael O, McLaren DG, Tommet D, Mungas D, Jones RN; for the Alzheimer's Disease Neuroimaging Initiative (2012) Coevolution of brain structures in amnestic mild cognitive impairment. Neuroimage 66C:449456. CrossRef Medline

Corder EH, Saunders AM, Strittmatter WJ, Schmechel DE, Gaskell PC, Small GW, Roses AD, Haines JL, Pericak-Vance MA (1993) Gene dose of apolipoprotein E type 4 allele and the risk of Alzheimer's disease in late onset families. Science 261:921-923. CrossRef Medline

Driscoll I, Davatzikos C, An Y, Wu X, Shen D, Kraut M, Resnick SM (2009) Longitudinal pattern of regional brain volume change differentiates normal aging from MCI. Neurology 72:1906-1913. CrossRef Medline

Drzezga A, Becker JA, Van Dijk KR, Sreenivasan A, Talukdar T, Sullivan C, Schultz AP, Sepulcre J, Putcha D, Greve D, Johnson KA, Sperling RA (2011) Neuronal dysfunction and disconnection of cortical hubs in nondemented subjects with elevated amyloid burden. Brain 134:1635-1646. CrossRef Medline

Engvig A, Fjell AM, Westlye LT, Moberget T, Sundseth $\varnothing$, Larsen VA, Walhovd KB (2010) Effects of memory training on cortical thickness in the elderly. Neuroimage 52:1667-1676. CrossRef Medline

Fischl B, Salat DH, Busa E, Albert M, Dieterich M, Haselgrove C, van der Kouwe A, Killiany R, Kennedy D, Klaveness S, Montillo A, Makris N, Rosen B, Dale AM (2002) Whole brain segmentation: automated labeling of neuroanatomical structures in the human brain. Neuron 33:341355. CrossRef Medline

Fischl B, van der Kouwe A, Destrieux C, Halgren E, Ségonne F, Salat DH, Busa E, Seidman LJ, Goldstein J, Kennedy D, Caviness V, Makris N, Rosen B, Dale AM (2004) Automatically parcellating the human cerebral cortex. Cereb Cortex 14:11-22. CrossRef Medline

Fjell AM, Walhovd KB, Fennema-Notestine C, McEvoy LK, Hagler DJ, Hol- 
land D, Brewer JB, Dale AM (2009) One-year brain atrophy evident in healthy aging. J Neurosci 29:15223-15231. CrossRef Medline

Fjell AM, Walhovd KB, Fennema-Notestine C, McEvoy LK, Hagler DJ, Holland D, Brewer JB, Dale AM; Alzheimer's Disease Neuroimaging Initiative (2010) CSF biomarkers in prediction of cerebral and clinical change in mild cognitive impairment and Alzheimer's disease. J Neurosci 30:20882101. CrossRef Medline

Fjell AM, Westlye LT, Grydeland H, Amlien I, Espeseth T, Reinvang I, Raz N, Dale A, Walhovd K (2012) Accelerating cortical thinning: unique to dementia or universal in aging? Cereb Cortex. Advance online publication. Retrieved Dec. 12, 2012. doi:10.1093/cercor/bhs379. CrossRef Medline

Folstein MF, Folstein SE, McHugh PR (1975) "Mini-mental state". A practical method for grading the cognitive state of patients for the clinician. J Psychiatr Res 12:189-198. CrossRef Medline

Goedert M, Spillantini MG (2006) A century of Alzheimer's disease. Science 314:777-781. CrossRef Medline

Gunning-Dixon FM, Raz N (2000) The cognitive correlates of white matter abnormalities in normal aging: a quantitative review. Neuropsychology 14:224-232. CrossRef Medline

Holland D, Brewer JB, Hagler DJ, Fennema-Notestine C, Dale AM; Alzheimer's Disease Neuroimaging Initiative (2009) Subregional neuroanatomical change as a biomarker for Alzheimer's disease. Proc Natl Acad Sci U S A 106:20954-20959. CrossRef Medline

Holland D, Dale AM; Alzheimer's Disease Neuroimaging Initiative (2011) Nonlinear registration of longitudinal images and measurement of change in regions of interest. Med Image Anal 15:489-497. CrossRef Medline

Holland D, McEvoy LK, Dale AM; Alzheimer's Disease Neuroimaging Initiative (2012) Unbiased comparison of sample size estimates from longitudinal structural measures in ADNI. Hum Brain Mapp 33:2586-2602. CrossRef Medline

Jack CR Jr, Petersen RC, Xu YC, Waring SC, O’Brien PC, Tangalos EG, Smith GE, Ivnik RJ, Kokmen E (1997) Medial temporal atrophy on MRI in normal aging and very mild Alzheimer's disease. Neurology 49:786-794. CrossRef Medline

Jack CR Jr, Knopman DS, Jagust WJ, Shaw LM, Aisen PS, Weiner MW, Petersen RC, Trojanowski JQ (2010) Hypothetical model of dynamic biomarkers of the Alzheimer's pathological cascade. Lancet Neurol 9:119-128. CrossRef Medline

Jack CR Jr, Albert MS, Knopman DS, McKhann GM, Sperling RA, Carrillo MC, Thies B, Phelps CH (2011) Introduction to the recommendations from the National Institute on Aging-Alzheimer's Association workgroups on diagnostic guidelines for Alzheimer's disease. Alzheimers Dement 7:257-262. CrossRef Medline

Jagust W (2013) Vulnerable neural systems and the borderland of brain aging and neurodegeneration. Neuron 77:219-234. CrossRef Medline

Jennings JR, Mendelson DN, Muldoon MF, Ryan CM, Gianaros PJ, Raz N, Aizenstein H (2012) Regional grey matter shrinks in hypertensive individuals despite successful lowering of blood pressure. J Hum Hypertens 26:295-305. CrossRef Medline

Jones DT, Machulda MM, Vemuri P, McDade EM, Zeng G, Senjem ML, Gunter JL, Przybelski SA, Avula RT, Knopman DS, Boeve BF, Petersen RC, Jack CR Jr (2011) Age-related changes in the default mode network are more advanced in Alzheimer disease. Neurology 77:1524-1531. CrossRef Medline

Laird AR, Eickhoff SB, Li K, Robin DA, Glahn DC, Fox PT (2009) Investigating the functional heterogeneity of the default mode network using coordinate-based meta-analytic modeling. J Neurosci 29:14496-14505. CrossRef Medline

Leritz EC, Salat DH, Williams VJ, Schnyer DM, Rudolph JL, Lipsitz L, Fischl B, McGlinchey RE, Milberg WP (2011) Thickness of the human cerebral cortex is associated with metrics of cerebrovascular health in a normative sample of community dwelling older adults. Neuroimage 54:2659-2671. CrossRef Medline

Leung KK, Ridgway GR, Ourselin S, Fox NC; Alzheimer's Disease Neuroimaging Initiative (2012) Consistent multi-time-point brain atrophy estimation from the boundary shift integral. Neuroimage 59:3995-4005. CrossRef Medline

McDonald CR, McEvoy LK, Gharapetian L, Fennema-Notestine C, Hagler DJ Jr, Holland D, Koyama A, Brewer JB, Dale AM; Alzheimer's Disease Neuroimaging Initiative (2009) Regional rates of neocortical atrophy from normal aging to early Alzheimer disease. Neurology 73:457-465. CrossRef Medline

Morris JC (1993) The Clinical Dementia Rating (CDR): current version and scoring rules. Neurology 43:2412-2414. Medline

Murphy EA, Holland D, Donohue M, McEvoy LK, Hagler DJ Jr, Dale AM, Brewer JB; Alzheimer's Disease Neuroimaging Initiative (2010) Sixmonth atrophy in MTL structures is associated with subsequent memory decline in elderly controls. Neuroimage 53:1310-1317. CrossRef Medline

Nelson PT, Head E, Schmitt FA, Davis PR, Neltner JH, Jicha GA, Abner EL, Smith CD, Van Eldik LJ, Kryscio RJ, Scheff SW (2011) Alzheimer's disease is not "brain aging": neuropathological, genetic, and epidemiological human studies. Acta Neuropathol 121:571-587. CrossRef Medline

Nelson PT, Alafuzoff I, Bigio EH, Bouras C, Braak H, Cairns NJ, Castellani RJ, Crain BJ, Davies P, Del Tredici K, Duyckaerts C, Frosch MP, Haroutunian V, Hof PR, Hulette CM, Hyman BT, Iwatsubo T, Jellinger KA, Jicha GA, Kövari E, et al. (2012) Correlation of Alzheimer disease neuropathologic changes with cognitive status: a review of the literature. J Neuropathol Exp Neurol 71:362-381. CrossRef Medline

Nyberg L, Kim AS, Habib R, Levine B, Tulving E (2010) Consciousness of subjective time in the brain. Proc Natl Acad Sci U S A 107:22356-22359. CrossRef Medline

Nyberg L, Lövdén M, Riklund K, Lindenberger U, Bäckman L (2012) Memory aging and brain maintenance. Trends Cogn Sci 16:292-305. CrossRef Medline

Persson J, Pudas S, Lind J, Kauppi K, Nilsson LG, Nyberg L (2012) Longitudinal structure-function correlates in elderly reveal MTL dysfunction with cognitive decline. Cereb Cortex 22:2297-2304.

Raichle ME, MacLeod AM, Snyder AZ, Powers WJ, Gusnard DA, Shulman GL (2001) A default mode of brain function. Proc Natl Acad Sci U S A 98:676-682. CrossRef Medline

Raz N, Lindenberger U, Rodrigue KM, Kennedy KM, Head D, Williamson A, Dahle C, Gerstorf D, Acker JD (2005) Regional brain changes in aging healthy adults: general trends, individual differences and modifiers. Cereb Cortex 15:1676-1689. CrossRef Medline

Reuter M, Schmansky NJ, Rosas HD, Fischl B (2012) Within-subject template estimation for unbiased longitudinal image analysis. Neuroimage 61:1402-1418. CrossRef Medline

Rey A (1964) L'examen clinique en psychologie. Paris: Presses Univeritaires de France.

Rodrigue KM, Raz N (2004) Shrinkage of the entorhinal cortex over five years predicts memory performance in healthy adults. J Neurosci 24:956963. CrossRef Medline

Schacter DL, Addis DR, Buckner RL (2007) Remembering the past to imagine the future: the prospective brain. Nat Rev Neurosci 8:657-661. CrossRef Medline

Shaw LM, Vanderstichele H, Knapik-Czajka M, Clark CM, Aisen PS, Petersen RC, Blennow K, Soares H, Simon A, Lewczuk P, Dean R, Siemers E, Potter W, Lee VM, Trojanowski JQ; Alzheimer's Disease Neuroimaging Initiative (2009) Cerebrospinal fluid biomarker signature in Alzheimer's disease neuroimaging initiative subjects. Ann Neurol 65:403-413. CrossRef Medline

Sperling RA, Aisen PS, Beckett LA, Bennett DA, Craft S, Fagan AM, Iwatsubo T, Jack CR Jr, Kaye J, Montine TJ, Park DC, Reiman EM, Rowe CC, Siemers E, Stern Y, Yaffe K, Carrillo MC, Thies B, Morrison-Bogorad M, Wagster MV, et al. (2011) Toward defining the preclinical stages of Alzheimer's disease: recommendations from the National Institute on Aging-Alzheimer's Association workgroups on diagnostic guidelines for Alzheimer's disease. Alzheimers Dement 7:280-292. CrossRef Medline

Squire LR, van der Horst AS, McDuff SG, Frascino JC, Hopkins RO, Mauldin KN (2010) Role of the hippocampus in remembering the past and imagining the future. Proc Natl Acad Sci U S A 107:19044-19048. CrossRef Medline

Strozyk D, Blennow K, White LR, Launer LJ (2003) CSF Abeta 42 levels correlate with amyloid-neuropathology in a population-based autopsy study. Neurology 60:652-656. CrossRef Medline

Thompson WK, Holland D; Alzheimer's Disease Neuroimaging Initiative (2011) Bias in tensor based morphometry Stat-ROI measures may result in unrealistic power estimates. Neuroimage 57:1-4. CrossRef Medline

Valenzuela MJ, Sachdev P, Wen W, Chen X, Brodaty H (2008) Lifespan mental activity predicts diminished rate of hippocampal atrophy. PLoS One 3:e2598. CrossRef Medline

Walhovd KB, Fjell AM, Dale AM, McEvoy LK, Brewer J, Karow DS, Salmon 
DP, Fennema-Notestine C; Alzheimer's Disease Neuroimaging Initiative (2010) Multi-modal imaging predicts memory performance in normal aging and cognitive decline. Neurobiol Aging 31:1107-1121. CrossRef Medline
Zatorre RJ, Fields RD, Johansen-Berg H (2012) Plasticity in gray and white: neuroimaging changes in brain structure during learning. Nat Neurosci 15:528-536. CrossRef Medline 